\title{
Correction to: A study on stability of active layer of polymer solar cells: effect of UV-visible light with different conditions
}

\author{
Umer Mehmood ${ }^{1,2} \cdot$ Khalil Harrabi $^{1,3} \cdot$ Ibnelwaleed A. Hussein $^{4}$. \\ Nagendiran Shanmugam ${ }^{5} \cdot$ A. Mekki $^{3} \cdot$ M. Mekki ${ }^{3} \cdot$ M. A. McLachlan ${ }^{6}$
}

Published online: 11 June 2019

๑) Springer-Verlag GmbH Germany, part of Springer Nature 2019

\section{Correction to: Polym. Bull. (2019) 76:525-537 https://doi.org/10.1007/s00289-018-2368-0}

The original article was published with incorrect affiliation of Prof. Ibnelwaleed Hussein as well as the project number in the acknowledgment.

The affiliation of Prof. Ibnelwaleed Hussein is Gas Processing Center, Qatar University, Doha, Qatar.

The correct project number of the funding is \#12 ENE2379-04 instead of \#ENE2379-04.

Publisher's Note Springer Nature remains neutral with regard to jurisdictional claims in published maps and institutional affiliations.

The original article can be found online at https://doi.org/10.1007/s00289-018-2368-0.

Khalil Harrabi

harrabi@kfupm.edu.sa

1 Center of Research Excellence, Renewable Energy (CoRE-RE), Research Institute (RI),

King Fahd University of Petroleum and Minerals (KFUPM), P.O. Box 5050, Dhahran 31261,

Kingdom of Saudi Arabia

2 Department of Polymer and Process Engineering, University of Engineering and Technology

Lahore, Lahore, Pakistan

3 Department of Physics, KFUPM, P.O. Box 5050, Dhahran 31261, Kingdom of Saudi Arabia

4 Gas Processing Center, Qatar University, Doha, Qatar

5 Chemical Engineering Department, KFUPM, Dhahran, Kingdom of Saudi Arabia

6 Department of Materials and Centre for Plastic Electronics, Imperial College London,

London SW7 2AZ, UK 